\title{
Laparoscopic sacral colpopexy versus total vaginal mesh for vault prolapse; comparison of cohorts
}

\author{
Mariëlla I. J. Withagen • Mark E. Vierhout • \\ Alfredo L. Milani • Guido H. H. Mannaerts • \\ Kirsten B. Kluivers • Robin M. F. van der Weiden
}

Received: 6 December 2012 / Accepted: 21 January 2013 /Published online: 10 February 2013

(C) Springer-Verlag Berlin Heidelberg 2013

\begin{abstract}
The surgical treatment of vaginal vault prolapse can either be performed by the vaginal or the abdominal (laparoscopic) route. The objective of this study was to compare the laparoscopic sacral colpopexy (LSC) and total vaginal mesh (TVM) for vaginal vault prolapse. This study compared a prospective cohort of LSC with bone-anchor fixation and mesh limited to the apex to a prospective cohort of TVM as treatment modalities in patients with a symptomatic vaginal vault prolapse (pelvic organ prolapsequantification (POP-Q) point $\mathrm{C} \geq-3$ ). Primary outcome was failure in the apical compartment after 6 month follow-up, defined as POP-Q stage $\geq$ II with prolapse complaints or retreatment in apical compartment. Based on an overall failure in all compartments of $23 \%$ in the LSC group and $57 \%$ in the TVM group, 29 patients would be needed in each group with a power of $80 \%$ and alpha 0.05 . Ninety-seven women were included, $45 \mathrm{LSC}$ and $52 \mathrm{TVM}$. The failure rate of symptomatic vault prolapse was $1(2 \%)$ in each group $(p=0.99)$. The failure rate (POP stage $\geq$ II) in any compartment was 23 (51\%)
\end{abstract}

M. I. J. Withagen • M. E. Vierhout $\cdot$ K. B. Kluivers

Department of Obstetrics and Gynaecology, Radboud University

Nijmegen Medical Centre, Nijmegen, The Netherlands

A. L. Milani

Department of Obstetrics and Gynaecology, Reinier de Graaf

Group, Delft, The Netherlands

G. H. H. Mannaerts

Department of Surgery, Sint Franciscus Gasthuis, Rotterdam,

The Netherlands

R. M. F. van der Weiden $(\square)$

Department of Obstetrics and Gynaecology, Sint Franciscus

Gasthuis, 3045 PM,

Rotterdam, The Netherlands

e-mail: rmfvdwei@knmg.nl in the LSC group and 11 (21\%) in the TVM group ( $p=0.002)$. Each technique had its own type of complications. Short-term failure rates in the apical compartment after TVM and LSC were similar. In case of anterior or posterior prolapsed, additional mesh insertion or additional vaginal colporrhaphy is indicated in LSC surgery.

Keywords Bone anchor - Laparoscopic sacral colpopexy · Pelvic organ prolapse $\cdot$ Vaginal mesh $\cdot$ Vaginal vault

\section{Introduction}

The incidence of post-hysterectomy vaginal vault prolapse that requires surgery has been estimated at 1.3 per 1,000 women-years [1]. The risk of pelvic organ prolapse surgery was 4.7 times higher in women whose initial hysterectomy was indicated by prolapsed [1]. The surgical treatment of vaginal vault prolapse can either be performed by the vaginal (e.g., vaginal sacrospinous colpopexy and total vaginal mesh (TVM), involving mesh placement in the anterior, and apical and posterior compartments) or the abdominal route (e.g., sacral colpopexy). A Cochrane systematic review and meta-analysis on the topic has shown that for the treatment of vaginal vault prolapse the abdominal sacral colpopexy was the superior procedure compared with vaginal sacrospinous colpopexy in terms of a lower rate of recurrent vault prolapse and less dyspareunia [2]. Vaginal sacrospinous colpopexy was, however, quicker and cheaper to perform and women returned earlier to activities of daily living. Laparoscopic sacral colpopexy (LSC) provides the potential to combine the success rate of an abdominal approach with the faster recovery associated with a minimally invasive technique. The success rate of LSC has been reported to be $90-100 \%$ for the apical compartment [3-8]. 
TVM aims at suspension of the apical compartment by means of a bilateral sacrospinous ligament fixation. The success rate of a TVM has been reported to be 96 to $99 \%$ for the apical compartment and $91 \%$ for all the compartments $[9,10]$.

Since the recent publication of the update of the FDA notification on complications of surgical mesh for transvaginal repair of POP, it is even more important to consider which treatment of apical compartment prolapse should be used in the individual patient [11]. Both abdominal and vaginal techniques treat the apical compartment, but the techniques are very different and not many gynecologists perform both procedures. As a result, only limited data are available that compare these two techniques. In a recent randomized controlled trial, success rate in all vaginal compartments was $77 \%$ for LSC as compared with $43 \%$ in the TVM group [12].

The aim of this study was to compare LSC and TVM with regard to the management of vaginal vault prolapse in centers with special expertise in either LSC or TVM.

\section{Methods}

This study compared two prospective observational cohorts of consecutive women with symptomatic vault prolapse referred to three centers: Sint Franciscus Gasthuis (SFG), Rotterdam, Radboud University Nijmegen Medical Centre (RUNMC), and Reinier de Graaf Group (RdGG) Delft, the Netherlands. SFG is specialized in LSC with bone-anchor fixation and at the time of the inclusion TVM was not an available therapy in this centre. Both RdGG and RUNMC are specialized in pelvic organ prolapse surgery, including TVM technique. At the time of the inclusion, LSC was not an available therapy in these centers.

Patients with a symptomatic vaginal vault prolapse with point C of the Pelvic Organ Prolapse Quantification (POP-Q) examination $\geq-3$ were included in the study [13]. Exclusion criteria were the inability to understand Dutch, pregnancy or the consideration of pregnancy in the future, a compromised immune system, and treatment for malignancy in the past. Additional exclusion criteria for the LSC were a former rectosigmoid resection, extensive intra-abdominal/pelvic adhesions and a body mass index of $>40 \mathrm{~kg} / \mathrm{m}^{2}$.

Approval from the Central Medical Ethics Committee in Rotterdam, the Netherlands was obtained for the LSC cohort study on 22 of December 2004. The data concerning the TVM patients were collected as part of an ongoing outcome registration project, which was approved by the CME/IRB on 19th April 2006. All patients provided written informed consent before participation and were recruited between July 2004 and November 2009.

Baseline as well as postoperative evaluation after 6 weeks and 6 months included a medical history, a gynecologic investigation including a POP-Q examination, and a validated urogynecological questionnaire, which contains the Dutch validated Urogenital Distress Inventory (UDI), Defecatory Distress Inventory (DDI), and the Incontinence Impact Questionnaire (IIQ) [14, 15].

In both groups the patients received, a single prophylactic dose of antibiotics. All LSC were performed by two of the authors together (RW and GM) using bone anchor fixation [16]. The operative procedure can be summarized as follows: after developing the presacral avascular plane, the cortical bone of the sacral segment 3 is penetrated in the midline with the laparoscopic bone anchor. Fixation to the sacrum is performed with a selftapping titanium Corkscrew Suture or with flat headed titanium screws. A $4.0 \times 3.0-\mathrm{cm}$ piece of monofilament knitted polypropylene mesh (Gynemesh Soft, Ethicon, Norderstedt, Germany) was sutured to the apical part of the posterior vaginal wall with four mersilene $1-0$ sutures (Ethicon, Norderstedt, Germany) and was subsequently sutured to the polyester-2 ligatures attached to the bone anchor. The mesh was covered with peritoneum placing it in a retroperitoneal position. Since the rate of vaginal mesh exposure is significantly higher when abdominal surgery is combined with vaginal surgery [17] and placement of a posterior mesh might increase the risk of postoperative complications in patients without a patent posterior prolapse [18], additional prolapse procedures were not performed concomitantly. We anticipated on a low rate of postoperative cystocele and rectocele since fixation of the vaginal apex to sacral segment 3 restores the natural axis of the vagina [19-21].

All TVM procedures were performed by four gynecologists who were formally trained for the tension-free vaginal mesh procedure as described in the paper by Fatton et al. prior to the start of this study [22]. As recommended, a full thickness midline incision was made through the fibromuscular wall of the vagina in order to reduce the known risk of mesh exposure. The TVM was placed as one sheet and not divided, as described by Milani et al. [9]. The TVM procedure was in principle not combined with continence surgery to avoid complications [23]; however, in one case the protocol was ignored.

Primary outcome was failure in the apical compartment, defined as apical POP-Q stage $\geq$ II with prolapse complaints or re-treatment in the apical compartment (failure outcome I). For secondary outcomes four different definitions for failure were tested:

- Failure outcome II: POP-Q stage $\geq$ II in one or more compartment(s).

- Failure outcome III: POP-Q stage $\geq$ II in one or more compartment(s) with prolapse complaints or re-treatment.

- Failure outcome IV: POP-Q at or beyond hymen in one or more compartment(s) with prolapse complaints or retreatment.

- Failure outcome V: prolapse complaints or re-treatment. 
Prolapse complaints were considered present if patients responded affirmative to the questions of the UDI referring to seeing or feeling a vaginal bulge and the experience of at least a little bother from either of these symptoms [14]. Data on symptom scores of the UDI, DDI, and IIQ questionnaires, duration of surgery, blood loss, length of hospitalization, and complications were collected. Pain was a secondary outcome as well and considered significant in case a patient responded "yes, moderately to quite a bit" to the question "Do you experience pain in the lower abdomen or genital region?" Dyspareunia was considered significant in case a patient responded "yes; moderately to quite a bit" to the question "Do you experience pain during intercourse?" Stress urinary incontinence was considered significant in case a patient responded "yes, moderately to quite a bit" to the UDI question "Do you experience urinary leakage during physical activity, coughing, or sneezing?"

Sample size calculation prior to the comparison study was performed as follows: given the success rates for the apical compartment in literature of 90-100\% [3-7] after LSC and $96 \%$ after TVM $[9,10]$, we hypothesized that we would not find a significant difference in primary outcome. Based on an overall failure in all compartments of $23 \%$ in the LSC group and $57 \%$ in the TVM group [12], 29 patients would be needed in each group to detect a difference of $34 \%$ in failure rate with a power of $80 \%$ and alpha 0.05 .

Continuous variables were analyzed using the independentsamples $t$ test to compare means, the Mann-Whitney $U$ test to compare independent medians and the Wilcoxon signed-rank test to compare related medians. Categorical variables were compared using the Chi-square test and the Fisher exact test in case of small numbers. Related samples were compared using the paired-samples $t$ test to compare means. A $p$ value of $<0.05$ was considered statistically significant. After using the Bonferroni correction for multiple testing for the eight different POP-Q points, the $p$ value for statistical significance regarding these points was lowered from 0.05 to 0.006 (alpha 0.05). Statistical analysis was performed using Statistical Package for the Social Sciences, version 18.0 (SPSS inc., Chicago, IL).
Findings

Forty-five women were included in the LSC group and 52 women were included in the TVM group. A flowchart of the two groups is presented in Fig. 1. All women undergoing LSC and 20 out of 52 (38 \%) undergoing TVM have previously been described [9, 24]. Baseline characteristics are shown in Table 1. The TVM group had significantly more patients with overall a higher stage of POP; however, the apical compartment prolapse was similar in the two groups (point $\mathrm{C}$, Table 1). The 2 patients with a POP-Q stage I and point $\mathrm{C} \geq-3$ in the LSC group both experienced bulging symptoms.

Peri- and postoperative data are shown in Table 2. POP-Q measurements are shown in Table 3. Improvement was found for each compartment in both groups. No difference was found in the improvement of the apical compartment between the two cohorts.

In Table 4, failure rates for various failure definitions are shown. The failure rate of symptomatic vault prolapse (failure I: apical compartment POP stage $\geq$ II with prolapse complaints or apical re-treatment) was $2 \%$ in de LSC group and $2 \%$ in de TVM group $(p=0.99)$. Definitions considering the apical compartment with or without prolapse complaints (I, II apical) showed similar failure rates between the groups. However, when definitions of failure included other compartments or prolapse complaints alone (II-V), the LSC group had a significant higher failure rate compared with the TVM group.

Effect of surgery on symptom bother and health related quality of life scores is shown in Table 5. UDI domain score of genital prolapse, overactive bladder, obstructive micturition, and pain improved significantly after surgery in both groups. The domain score of genital prolapse 6 months after TVM was significantly lower (less bother) compared with the score of de the LSC group.
Fig. 1 Patient enrollment and follow-up

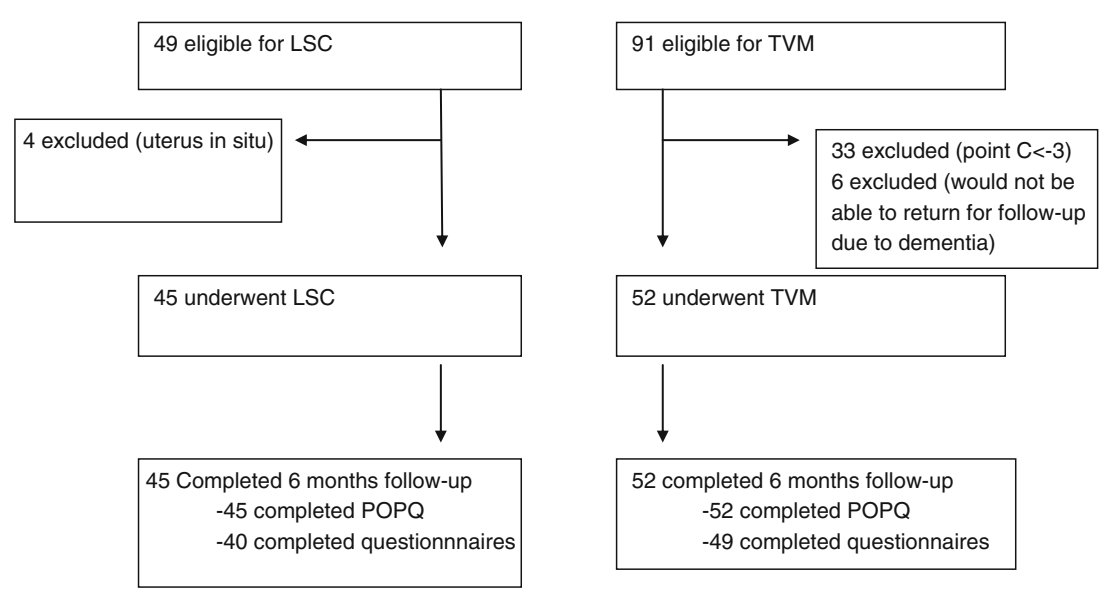


Table 1 Patient characteristics

$P O P$ pelvic organ prolapse, $P O P-Q$ pelvic organ prolapse quantification, $L S C$ laparoscopic sacral colpopexy, TVM total vaginal mesh

${ }^{\mathrm{a}}$ Data presented as mean (standard deviation), and $p$ value calculated with

independent sample $t$ test

${ }^{\mathrm{b}}$ Data presented as median (range), and $p$ value calculated with Mann-Whitney $U$ test

${ }^{\mathrm{c}}$ Data presented as number of patients (in percent), and $p$ value calculated with Chi-square test and the Fisher exact test in case of small numbers

${ }^{\mathrm{d}} \mathrm{POP}-\mathrm{Q}$ point $\mathrm{C} \geq-3$

\begin{tabular}{|c|c|c|c|}
\hline Characteristics & $\operatorname{LSC}(n=45)$ & TVM $(n=52)$ & $p$ value \\
\hline Age (years) ${ }^{\mathrm{a}}$ & $65.6(9.7)$ & $69.1(11.6)$ & 0.12 \\
\hline Parity (number) $^{\mathrm{b}}$ & $2(0-6)$ & $3(0-6)$ & 0.12 \\
\hline BMI $\left(\mathrm{kg} / \mathrm{m}^{2}\right)^{\mathrm{a}}$ & $25.6(3.1)$ & $26.2(3.6)$ & 0.33 \\
\hline Comorbidity $^{\mathrm{c}}$ & $5(11 \%)$ & $25(48 \%)$ & $<0.001$ \\
\hline \multicolumn{4}{|l|}{ Previous surgery ${ }^{\mathrm{c}}$} \\
\hline Abdominal hysterectomy & $18(40 \%)$ & $13(25 \%)$ & 0.15 \\
\hline Vaginal hysterectomy & $27(60 \%)$ & $39(75 \%)$ & 0.11 \\
\hline Anterior colporraphy & $24(53 \%)$ & $23(44 \%)$ & 0.54 \\
\hline Anterior mesh procedure & $0(0 \%)$ & $1(2 \%)$ & 0.54 \\
\hline Posterior colporrhaphy & $24(53 \%)$ & $18(35 \%)$ & 0.11 \\
\hline Sacrospinous ligament fixation & $0(0 \%)$ & $2(4 \%)$ & 0.12 \\
\hline Sacrocolpopexy & $0(0 \%)$ & $2(4 \%)$ & 0.17 \\
\hline Colpocleisis & $0(0 \%)$ & $2(4 \%)$ & 0.17 \\
\hline Previous POP procedure & $29(64 \%)$ & $28(54 \%)$ & 0.29 \\
\hline More than one POP procedure & $2(4 \%)$ & $6(12 \%)$ & 0.14 \\
\hline Previous incontinence surgery ${ }^{c}$ & $9(20 \%)$ & $4(8 \%)$ & 0.08 \\
\hline \multicolumn{4}{|l|}{ Overall POP-Q stage ${ }^{c}$} \\
\hline$I^{d}$ & $2(4 \%)$ & $0(0 \%)$ & 0.21 \\
\hline II & $31(69 \%)$ & $5(10 \%)$ & $<0.001$ \\
\hline III & $12(27 \%)$ & $43(83 \%)$ & $<0.001$ \\
\hline IV & $0(0 \%)$ & $4(7 \%)$ & 0.08 \\
\hline Point $C^{b}$ & $0(-3$ to 4$)$ & $1(-3$ to 9$)$ & 0.41 \\
\hline
\end{tabular}

\section{Discussion}

Comparison of LSC with bone anchor fixation and mesh limited to the apex to TVM revealed significantly higher overall POP-Q failure rate (symptomatic failure in any of the compartments) in the LSC group with no statistically significant differences regarding the vaginal vault. We anticipated a positive effect of fixation of the vaginal apex also on the anterior and posterior compartment due to restoration of the vaginal axis [19-21]. However, the results in the LSC cohort demonstrate that apical support alone does not adequately prevent prolapse of the anterior and posterior compartment and support the necessity of anterior and posterior fixation of the vaginal cuff at the time of LSC. This finding also has its repercussions on the power analysis which was based on overall failure rates in all compartments.

Different types of complications were seen in the two groups. Scores in the UDI domain genital prolapse improved significantly in both groups, but the postoperative genital prolapse score was lower (less complaints) in the TVM group.

The strengths of this study are the prospective design of the study and the use of standardized and validated instruments of measurement. Furthermore, since comparative data on these two main techniques for vaginal vault prolapse are limited, this is an actual and highly relevant topic in urogynecological practice [25]. The short follow-up of 6 months and the nonrandomized selection of intervention were important limitations of this study. Furthermore, an independent clinical investigator who was not involved in the management of the patients would ideally have performed the pre- and postoperative examinations.

Sometimes the vault may be prolapsed clinically to a significant extent and yet be measured as POP-Q stage I, demonstrating a limitation of the POP-Q scoring system with respect to the apical compartment [26]. We had two patients, included in the LSC cohort, with a vault prolapse and vaginal bulge symptoms (UDI score on domain genital prolapse $\geq 16.6$ ) despite an overall POP $<$ stage II. In these two patients, the POPQ point $\mathrm{C}$ was $\geq-3 \mathrm{~cm}$.

The high success rates of the LSC and TVM in the apical compartment were comparable to the rates reported in literature [3-9, 27]. However, the overall failure rate of $51 \%$ in the LSC group was high compared with the $23 \%$ failure rate after two years follow-up reported in a recent randomized controlled trial on LSC versus TVM for vaginal vault prolapse [12]. This may be explained by the fact that mesh was only applied to the apex without combining LSC with 
Table 2 Peri- and postoperative data
TVT tension free vaginal tape-obturator system, $P O P$ pelvic organ prolapse, $L S C$ laparoscopic sacral colpopexy, TVM total vaginal mesh

${ }^{a}$ Data presented as number of patients (in percent), and $p$ value calculated with Chi-square test and the Fisher exact test in case of small numbers

${ }^{\mathrm{b}}$ Data presented as median (range), and $p$ value calculated with Mann-Whitney $U$ test

\begin{tabular}{|c|c|c|c|}
\hline Variable & $\operatorname{LSC}(n=45)$ & TVM $(n=52)$ & $p$ value \\
\hline (Concomitant) surgery ${ }^{\mathrm{a}}$ & $2(4 \%)$ & $1(2 \%)$ & 0.35 \\
\hline TVT-O & 0 & $1(2 \%)$ & 0.54 \\
\hline Laparoscopic adhesiolysis & $1(2 \%)$ & 0 & 0.46 \\
\hline Laparoscopic aspiration pseudocysts & $1(2 \%)$ & 0 & 0.46 \\
\hline Spinal analgesia ${ }^{\mathrm{a}}$ & 0 & $33(63 \%)$ & $<0.001$ \\
\hline Operating time $(\mathrm{min})^{\mathrm{b}}$ & $120(60-240)$ & $70(44-110)$ & $<0.001$ \\
\hline Blood loss $(\mathrm{ml})^{\mathrm{b}}$ & $50(10-100)$ & $100(50-1,300)$ & $<0.001$ \\
\hline Duration urinary catheter (days) ${ }^{\mathrm{b}}$ & $1(1)$ & $2(1-10)$ & $<0.001$ \\
\hline Hospital stay (days) ${ }^{\mathrm{b}}$ & $2(0-5)$ & $3(0-8)$ & $<0.001$ \\
\hline \multicolumn{4}{|l|}{ Complications $^{\mathrm{a}}$} \\
\hline Blood loss $>500 \mathrm{ml}$ & $0(0 \%)$ & $1(2 \%)$ & 0.54 \\
\hline Bladder perforation & $0(0 \%)$ & $1(2 \%)$ & 0.54 \\
\hline Repeat surgery for postoperative hemorrhage & $0(0 \%)$ & $1(2 \%)$ & 0.54 \\
\hline Hematoma & $0(0 \%)$ & $2(4 \%)$ & 0.28 \\
\hline Temporary urinary retention & $0(0 \%)$ & $10(19 \%)$ & 0.001 \\
\hline Conversion laparotomy due to injury ileum & $1(2 \%)$ & $0(0 \%)$ & 0.46 \\
\hline $\begin{array}{l}\text { Temporary neurologic complaints caused by } \\
\text { irritation left lumbar plexus }\end{array}$ & $1(2 \%)$ & $0(0 \%)$ & 0.46 \\
\hline \multicolumn{4}{|l|}{ Outcome/complications at follow-up 6 months ${ }^{\mathrm{a}}$} \\
\hline Cumulative mesh exposure & $1(2 \%)$ & $4(8 \%)$ & 0.19 \\
\hline Re-treatment for POP & $2(4 \%)$ & $0(0 \%)$ & 0.21 \\
\hline \multicolumn{4}{|l|}{ Pain (lower abdomen/genital area) } \\
\hline Baseline & $9 / 43(21 \%)$ & $11 / 44(25 \%)$ & 0.65 \\
\hline At 6 months & $1 / 40(3 \%)$ & $1 / 45(2 \%)$ & 0.50 \\
\hline De novo pain & $0(0 \%)$ & $0(0 \%)$ & 0.99 \\
\hline \multicolumn{4}{|l|}{ Dyspareunia } \\
\hline Baseline & $3 / 18(17 \%)$ & $4 / 17(24 \%)$ & 0.29 \\
\hline At 6 months & $3 / 21(14 \%)$ & $3 / 18(17 \%)$ & 0.33 \\
\hline De novo dyspareunia & 2/18 (11\%) & $1 / 17(6 \%)$ & 0.40 \\
\hline \multicolumn{4}{|l|}{ Stress urinary incontinence } \\
\hline Baseline & $3 / 43(7 \%)$ & $11 / 45(24 \%)$ & 0.02 \\
\hline At 6 months & $3 / 41(7 \%)$ & $5 / 46(11 \%)$ & 0.25 \\
\hline De novo stress urinary incontinence & $2 / 41(5 \%)$ & $2 / 41(5 \%)$ & 0.38 \\
\hline
\end{tabular}

anterior or posterior repairs (either laparoscopically applied mesh or with vaginal colporrhaphia) in the present study. In a cohort study on 22 LSC, an overall failure rate of $73 \%$ after 2 years was found when a mesh was attached to the apex and the posterior wall only [8]. Anterior mesh application during LSC therefore also seems important. Adequate level I support has a critical role on the position of the anterior and posterior vagina [28, 29]. However, this adequate level I support has not prevented the occurrence of anterior and posterior wall prolapse in many cases in the LSC group. Combining the LSC with anterior and/or posterior repair, either performed laparoscopically or vaginally, might have resulted in better overall results in the LSC group. After evaluation of these results this has now become the standard procedure in LSC.
Our overall success rate of the TVM was high compared with the results of Maher et al. [12], but in that study the follow-up was 1.5 years longer and 12 out of the 55 patients with TVM were considered as failures due to lost to followup in that study. Our success rate of the TVM was low compared with a previously published cohorts of a total mesh [9, 10].

In contrast with the results of the study by Maher et al. [12], the symptom score of genital prolapse after 6 months was significantly lower (less complaints) in the TVM group, compared with the LSC group. Recurrent prolapse symptoms in the LSC group generally arose from the untreated anterior or posterior compartment. The application of mesh to the apex only in the LSC group might also explain this difference. 
Table 3 POP-Q measurements at baseline and 6 months post surgery

\begin{tabular}{|c|c|c|c|c|c|c|c|}
\hline \multirow[t]{2}{*}{ POPQ point } & \multicolumn{2}{|l|}{ Baseline } & \multirow{2}{*}{$\begin{array}{l}p \text { value }^{\mathrm{a}} \\
\text { LSC versus TVM }\end{array}$} & \multicolumn{2}{|l|}{6 months } & \multirow{2}{*}{$\begin{array}{l}p \text { value }^{\mathrm{a}} \\
\text { LSC versus } \\
\text { TVM }\end{array}$} & \multirow{2}{*}{$\begin{array}{l}p \text { value }^{\mathrm{b}} \\
\text { within group } \\
\text { LSC/TVM }\end{array}$} \\
\hline & $\begin{array}{l}\text { LSC } \\
(n=45)\end{array}$ & $\begin{array}{l}\text { TVM } \\
(n=52)\end{array}$ & & $\operatorname{LSC}(n=45)$ & $\begin{array}{l}\text { TVM } \\
(n=52)\end{array}$ & & \\
\hline $\mathrm{Aa}$ & $-2(-3$ to 1$)$ & $3(-3$ to 3$)$ & $<0.001$ & $-2(-3$ to 0$)$ & $-3(-3$ to 0$)$ & $<0.001$ & $0.002 /<0.001$ \\
\hline $\mathrm{Ba}$ & $-2(-3$ to 3$)$ & $3(-2$ to 9$)$ & $<0.001$ & $-2(-3$ to 2$)$ & $-3(-3$ to 4$)$ & $<0.001$ & $0.005 /<0.001$ \\
\hline $\mathrm{C}$ & $0(-3$ to 4$)$ & $1(-3$ to 9$)$ & 0.41 & $-8(-8$ to -3$)$ & $-8(-10$ to 4$)$ & 0.074 & $<0.001 /<0.001$ \\
\hline $\mathrm{GH}$ & $3(2$ to 5$)$ & $5(2$ to 7$)$ & $<0.001$ & $3(2$ to 5$)$ & $3(2$ to 6$)$ & 0.21 & $1.00 /<0.001$ \\
\hline PB & $3(2$ to 3$)$ & $3(1$ to 7$)$ & 0.13 & $3(2$ to 3$)$ & $3(1$ to 6$)$ & $<0.001$ & $0.16 / 0.23$ \\
\hline TVL & $8(7$ to 9$)$ & $9(5$ to 10$)$ & $<0.001$ & $8(7$ to 9$)$ & $9(6$ to 10$)$ & $<0.001$ & $1.00 / 0.009$ \\
\hline Ap & $-2(-3$ to 2$)$ & $1(-3$ to 3$)$ & $<0.001$ & $-2(-3$ to 0$)$ & $-3(-3$ to 0$)$ & $<0.001$ & $<0.001 /<0.001$ \\
\hline Bp & $-2(-3$ to 2$)$ & $2(-3$ to 9$)$ & $<0.001$ & -2 ( -3 to 2$)$ & $-3(-3$ to 4$)$ & $<0.001$ & $0.001 /<0.001$ \\
\hline POP-Q stage anterior & $1(0$ to 3$)$ & $3(1$ to 4$)$ & $<0.001$ & $1(0$ to 3$)$ & $0(0$ to 3$)$ & $<0.001$ & $<0.001 /<0.001$ \\
\hline POP-Q stage apical & $2(0$ to 3$)$ & $3(0$ to 4$)$ & 0.357 & $0(0$ to 1$)$ & $0(0$ to 3$)$ & 0.31 & $0.016 /<0.001$ \\
\hline POP-Q stage posterior & $1(0$ to 3$)$ & $3(0$ to 4$)$ & $<0.001$ & $1(0$ to 3$)$ & $0(0$ to 3$)$ & $<0.001$ & $0.001 /<0.001$ \\
\hline Total POP-Q stage & $2(1$ to 3$)$ & $3(2$ to 4$)$ & $<0.001$ & $1(0$ to 3$)$ & $1(0$ to 3$)$ & $<0.001$ & $<0.001 /<0.001$ \\
\hline Change C & - & - & - & $7(5$ to 12$)$ & $7(3-19)$ & 0.97 & - \\
\hline
\end{tabular}

$P O P$ pelvic organ prolapse, $P O P-Q$ pelvic organ prolapse quantification, $L S C$ laparoscopic sacral colpopexy, TVM total vaginal mesh.

${ }^{\text {a }}$ Mann-Whitney $U$ test

${ }^{\mathrm{b}}$ Data presented as median (range)

${ }^{\text {a }}$ Wilcoxon signed-rank test

The types of complications were remarkably different between the two techniques. There was a high rate of temporary urinary retention in the TVM group. The complications with long lasting consequences were similar in both groups. Major complications such as bowel injury, de novo dyspareunia, de novo pain, and exposure did not differ between both groups in this study. In comparison with earlier studies on these two techniques, no major differences were found $[6,9,10,27]$. In the RCT of Maher et al. [12], the reoperation rate in the

Table 4 Failure at 6 months for different definitions

\begin{tabular}{|c|c|c|c|c|c|}
\hline Failure definition & $\operatorname{LSC}(N=45)$ & $\operatorname{TVM}(N=52)$ & $p$ value $^{\mathrm{a}}$ & OR $(95 \% \mathrm{CI})$ & $\mathrm{RR}(95 \% \mathrm{CI})$ \\
\hline $\begin{array}{l}\text { (I) Apical compartment POP-Q stage } \geq \text { II with prolapse } \\
\text { complaints or apical re-treatment }\end{array}$ & $1(2 \%)$ & $1(2 \%)$ & 0.99 & $1.1(0.07-18.7)$ & $1.0(0.9-1.1)$ \\
\hline (II) POP-Q stage $\geq$ II in one or more compartment & $23^{\mathrm{b}}(51 \%)$ & $11(21 \%)$ & 0.002 & $3.9(1.6-9.4)$ & $2.4(1.3-4.4)$ \\
\hline \multicolumn{6}{|l|}{ POP in every separate compartment } \\
\hline Anterior & $14^{\mathrm{c}}(31 \%)$ & $9(17 \%)$ & 0.11 & $2.2(0.8-5.6)$ & $1.8(1.0-2.2)$ \\
\hline Posterior & $10(22 \%)$ & $4(8 \%)$ & 0.04 & $2.2(1.0-11.8)$ & $2.9(1.0-8.6)$ \\
\hline Apical & $1^{\mathrm{d}}(2 \%)$ & $2(4 \%)$ & 0.39 & $0.6(0.1-5.9)$ & $0.5(0.1-5.7)$ \\
\hline $\begin{array}{l}\text { (III) Overall POP-Q stage } \geq \text { II with prolapse complaints } \\
\text { or re-treatment }\end{array}$ & $7 / 42(17 \%)$ & $1 / 52(2 \%)$ & 0.02 & $10.2(1.2-86.6)$ & $1.2(1.0-1.4)$ \\
\hline $\begin{array}{l}\text { (IV) POP at or beyond hymen with prolapse complaints or } \\
\text { re-treatment }\end{array}$ & $6 / 44(14 \%)$ & $1 / 52(2 \%)$ & 0.04 & $8.1(0.9-69.7)$ & $1.1(1.0-1.3)$ \\
\hline (V) Prolapse complaints or re-treatment & $12 / 41(29 \%)$ & $3 / 45(7 \%)$ & 0.006 & $5.8(1.5-22.4)$ & $1.3(1.1-1.6)$ \\
\hline
\end{tabular}

Data presented as numbers (in percent)

$P O P$ pelvic organ prolapse, $P O P-Q$ pelvic organ prolapse quantification, $L S C$ laparoscopic sacral colpopexy, $T V M$ total vaginal mesh, OR $=$ odds ratio, $95 \% C I 95 \%$ confidence interval, $R R$ relative risk

${ }^{\text {a }}$ Chi-square test and the Fisher exact test in case of small numbers

${ }^{\mathrm{b}}$ Including one re-sacrocolpopexy and one anterior colporrhaphy within 6 months

${ }^{\mathrm{c}}$ Including one anterior colporrhaphy within 6 months

${ }^{\mathrm{d}}$ Including one sacrocolpopexy within 6 months 
Table 5 Effect of surgery on symptoms and health-related quality of life scores

\begin{tabular}{|c|c|c|c|c|c|c|}
\hline \multirow[t]{2}{*}{ Domain } & \multicolumn{2}{|l|}{ Baseline } & \multicolumn{2}{|l|}{6 months } & \multirow{2}{*}{$\begin{array}{l}p \text { value within group } \\
\text { (LSC/TVM) }\end{array}$} & \multirow{2}{*}{$\begin{array}{l}p \text { value between groups } \\
\text { LSC versus TVM } \\
\text { baseline } / 6 \mathrm{~m}\end{array}$} \\
\hline & $\begin{array}{l}\text { LSC } \\
(n=43)\end{array}$ & $\begin{array}{l}\text { TVM } \\
(n=46)\end{array}$ & $\begin{array}{l}\text { LSC } \\
(n=40)\end{array}$ & $\begin{array}{l}\text { TVM } \\
(n=49)\end{array}$ & & \\
\hline \multicolumn{7}{|l|}{ UDI } \\
\hline Genital prolapsed & $67.9(30.2)$ & $63.0(18.7)$ & $11.3(22.5)$ & $2.0(9.9)$ & $<0.001 /<0.001$ & $0.49 / 0.01$ \\
\hline $\mathrm{OAB}$ & $34.6(26.0)$ & $32.2(26.8)$ & $17.6(19.2)$ & $15.4(19.7)$ & $<0.001 / 0.001$ & $0.68 / 0.59$ \\
\hline Incontinence & $16.3(20.7)$ & $24.2(26.8)$ & $10.6(17.4)$ & $15.9(21.8)$ & $0.11 / 0.10$ & $0.15 / 0.20$ \\
\hline Obstructive micturition & $34.5(24.8)$ & $28.1(29.9)$ & $15.4(21.8)$ & $12.2(23.8)$ & $<0.001 /<0.001$ & $0.28 / 0.51$ \\
\hline Pain & $25.4(24.8)$ & $27.7(27.6)$ & $12.5(15.9)$ & $10.1(16.8)$ & $0.001 /<0.001$ & $0.69 / 0.49$ \\
\hline \multicolumn{7}{|l|}{ DDI } \\
\hline Constipation & $12.7(19.8)$ & $14(18.7)$ & $11.1(20.4)$ & $8.2(15.1)$ & $0.36 / 0.12$ & $0.75 / 0.45$ \\
\hline Obstructed defecation & $13.4(14.6)$ & $12.0(17.1)$ & $7.5(11.1)$ & $9.1(13.4)$ & $0.003 / 0.10$ & $0.69 / 0.56$ \\
\hline Pain & $6.2(15.9)$ & $9.6(21.5)$ & $6.7(15.5)$ & $7.1(15.9)$ & $0.99 / 0.56$ & $0.40 / 0.89$ \\
\hline Incontinence & $4.4(11.7)$ & $9.8(15.8)$ & $5.0(10.1)$ & $4.3(8.8)$ & $0.99 / 0.03$ & $0.07 / 0.72$ \\
\hline \multicolumn{7}{|l|}{ IIQ } \\
\hline Physical functioning & $20.8(26.9)$ & $25.0(28.2)$ & $14.1(24.0)$ & $11.2(21.1)$ & $0.17 / 0.004$ & $0.50 / 0.56$ \\
\hline Mobility & $26.4(20.4)$ & $32.0(24.6)$ & $24.5(25.4)$ & $15.7(19.5)$ & $0.57 / 0.003$ & $0.25 / 0.08$ \\
\hline Social functioning & $12.4(11.9)$ & $15.9(18.1)$ & $7.6(13.9)$ & $6.7(10.6)$ & $0.10 / 0.01$ & $0.35 / 0.74$ \\
\hline Embarrassment & $12.6(20.7)$ & $21.8(26.1)$ & $7.2(13.9)$ & $6.9(12.3)$ & $0.15 / 0.002$ & $0.09 / 0.92$ \\
\hline Emotional health & $21.4(21.4)$ & $24.9(25.6)$ & $15.7(21.1)$ & $9.3(13.3)$ & $0.51 / 0.002$ & $0.51 / 0.10$ \\
\hline
\end{tabular}

UDI, DDI, and IIQ data presented as mean (standard deviation). Scores range between 0 (least bother) to 100 (maximum bother)

$U D I$ urogenital distress inventory, DDI defecatory distress inventory, IIQ incontinence impact questionnaire, LSC laparoscopic sacral colpopexy, TVM total vaginal mesh

${ }^{\text {a }}$ Paired $t$ test

${ }^{\mathrm{b}}$ Independent $t$ test

LSC group was significantly lower, compared with the reoperation rate in the TVM group. This discrepancy with our results might be explained by the shorter follow-up as mentioned before.

Reports on major complications have recently been published on both techniques subject to this study [12, 30-34]. In the LSC group injury of the bowels, bowel herniation though a port site and lumber/sacral osteomyelitis with sepsis are possible life-threatening complications [12, 30-32]. In this study, one serosal lesion to the ileum injury occurred. This injury was recognized immediately and sutured after conversion to a laparotomy [24]. In the TVM group, acute massive hemorrhage, retroperitoneal hematoma, and infected pelvic hematoma have been reported, indicating major, possible life-threatening complications as well [12, 33]. A FDA Public Health Notification update informed the USA public that "surgical mesh for transvaginal repair of POP is an area of continuing serious concern" and "serious complications associated with surgical mesh for transvaginal repair of POP are not rare" [11]. A definition for a serious complications was not given. Severe/serious complications, such as de novo dyspareunia, de novo pain, and exposure did not differ between both groups in this study.
The LSC and the TVM both involve a significant learning curve [35]. Both techniques are associated with potential serious complications. The FDA promulgated a number of recommendations including proper training of the surgeon, certification, and counseling of the patient. Therefore centralization of these procedures in the hands of surgeons with proven experience seems mandatory.

\section{Conclusions}

Although either procedures (LSC or TVM) will be adequate in most patients with vault prolapse, specific indications for either technique may exist. For example, in elderly women with comorbidity, spinal analgesics and shorter duration of surgery connected with TVM may be advantageous. Furthermore, in patients with known pelvic/abdominal adhesions a TVM procedure could be preferable. In young, healthy, sexually active women, the more superficial vaginal insertion of mesh can be avoided when choosing LSC. In order to make a deliberate choice between these two types of surgery and to improve the guidance to our patients, further evaluation with long-term follow-up of both procedures is required, preferably by welldesigned RCT's with a long-term follow-up of both procedures. 
Declaration of interest The authors report no conflicts of interest. The authors alone are responsible for the content and writing of the paper.

\section{References}

1. Dallenbach P, Kaelin-Gambirasio I, Dubuisson JB, Boulvain M (2007) Risk factors for pelvic organ prolapse repair after hysterectomy. Obstet Gynecol 110:625-632

2. Maher C, Feiner B, Baessler K, et al. (2010) Surgical management of pelvic organ prolapse in women. Cochrane Database Syst Rev 4:CD004014.

3. Agarwala N, Hasiak N, Shade M (2007) Laparoscopic sacral colpopexy with Gynemesh as graft material: experience and results. J Minim Invasive Gynecol 14:577-583

4. Ross JW, Preston M (2005) Laparoscopic sacrocolpopexy for severe vaginal vault prolapse: 5-year outcome. J Minim Invasive Gynecol 12:221-226

5. Cosson M, Rajabally R, Bogaert E et al (2002) Laparoscopic sacrocolpopexy, hysterectomy, and Burch colposuspension: feasibility and short-term complications of 77 procedures. JSLS 6:115119

6. Higgs PJ, Chua HL, Smith AR (2005) Long term review of laparoscopic sacrocolpopexy. BJOG 112:1134-1138

7. Price N, Slack A, Jackson SR (2011) Laparoscopic sacrocolpopexy: an observational study of functional and anatomical outcomes. Int Urogynecol J 22:77-82

8. North C, Ali-Ross N, Smith A, Reid F (2009) A prospective study of laparoscopic sacrocolpopexy for the management of pelvic organ prolapse. BJOG 116:1251-1257

9. Milani AL, Withagen MI, Vierhout ME (2009) Trocar-guided total tension-free vaginal mesh repair of post-hysterectomy vaginal vault prolapse. Int Urogynecol J 20:1203-1211

10. McDermott CD, Terry CL, Woodman PJ, Hale DS (2011) Surgical outcomes following total Prolift: colpopexy versus hysteropexy. Aust N Z J Obstet Gynaecol 51:61-66

11. FDA U.S. Food and Drug Administration. Medical Devices. Available at http://www.fda.gov/medicaldevices/safety/alertsandnotices/ publichealthnotifications/ucm061976.htm

12. Maher CF, Feiner B, DeCuyper EM, Nichlos CJ, Hickey KV, O'Rourke P (2011) Laparoscopic sacral colpopexy versus total vaginal mesh for vaginal vault prolapse: a randomized trial. Am J Obstet Gynecol 204(360):1-7

13. Bump RC, Mattiasson A, Bo K et al (1996) The standardization of terminology of female pelvic organ prolapse and pelvic floor dysfunction. Am J Obstet Gynecol 175:10-17

14. Van der Vaart CH, de Leeuw JR, Roovers JP, Heintz AP (2003) Measuring health-related quality of life in women with urogenital dysfunction: the urogenital distress inventory and incontinence impact questionnaire revisited. Neurourol Urodyn 22:97-104

15. Brummen HJ, Bruinse HW, Pol G, Heintz AP, Vaart CH (2006) Defecatory symptoms during and after the first pregnancy: prevalences and associated factors. Int Urogynecol J 17:224-230

16. van der Weiden RM, Withagen MI, Bergkamp AB, Mannaerts GH (2005) A new device for bone anchor fixation in laparoscopic sacrocolpopexy. The Franciscan laparoscopic bone anchor inserter. Surg Endosc 19:594-597
17. Visco AG, Weidner AC, Barber MD et al (2001) Vaginal mesh erosion after abdominal sacral colpopexy. Am J Obstet Gynecol 184:297-302

18. Antiphon P, Elard S, Benyoussef A, Fofana M, Yiou R, Gettman M et al (2004) Laparoscopic promontory sacral colpopexy: is the posterior recto-vaginal mesh mandatory. Eur Urol 45:655-661

19. Nichols DH, Milley PS, Randall CL (1970) Significance of restoration of normal vaginal depth and axis. Obstet Gynecol 36:251-256

20. Funt MI, Thompson JD, Birch H (1978) Normal vaginal axis. South Med J 71(1534-1535):1552

21. DeLancey JOL (2012) Surgery for cystocele III: do all cystoceles involve apical descent? Observations on cause and effect. Int Urogynecol J 23:665-667

22. Fatton B, Amblard J, Debodinance P, Cosson M, Jacquetin B (2007) Transvaginal repair of genital prolapse: preliminary results of a new tension-free vaginal mesh (Prolift technique) - a case series multicentric study. Int Urogynecol J 18:743-752

23. Withagen MI, Milani AL (2007) Which factors influenced the result of a tension free vaginal tape operation in a single teaching hospital? Acta Obstet Gynecol Scand 86:1136-1139

24. Withagen M, Vierhout M, Mannaerts G, van der Weiden R (2011) Laparoscopic sacrocolpopexy with bone anchor fixation: shortterm anatomic and functional results. Int Urogynecol 23:481-486

25. Bot-Robin V, Lucot JP, Giraudet G, Rubod C, Cosson M (2012) Use of vaginal mesh for pelvic organ prolapse repair: a literature review. Gynecol Surg 9:3-15

26. Barber MD, Brubaker L, Nygaard I, Wheeler TL, Schaffer J, Chen Z, Spino C, For the Pelvic Floor Disorders Network (2009) Defining success after surgery for pelvic organ prolapse. Obstet Gynecol 114:600-609

27. Sanses TV, Shahryarinejad A, Molden S, Hoskey KA, Abbasy S, Patterson D, Saks EK, Weber Lebrun EE, Gamble TL, King VG, Nguyen AL, Abed H, Young SB, Fellows' Pelvic Research Network (2009) Anatomic outcomes of vaginal mesh procedure (Prolift) compared with uterosacral ligament suspension and abdominal sacrocolpopexy for pelvic organ prolapse: a Fellows' Pelvic Research Network study. Am J Obstet Gynecol 201(519):1-8

28. DeLancey JOL (1992) Anatomic aspects of vaginal eversion after hysterectomy. Am J Obstet Gynecol 166:1717-1724

29. Lowder JL, ParkAJ ER et al (2008) The role of apical vaginal support in the appearance of anterior and posterior vaginal prolapse. Obstet Gynecol 111:152-157

30. Thubert T, Pourcher G, Deffieux X (2011) Small bowel volvulus following peritoneal closure using absorbable knotless device during laparoscopic sacral colpopexy. Int Urogynecol J 22:761-763

31. Klauschie J, Suozzi B, O’Brien M, McBride A (2009) A comparison of laparoscopic and abdominal sacral colpopexy: objective outcome and perioperative differences. Int Urogynecol J 20:273-279

32. Nossier S, Kim Y, Lind L, Winkler H (2010) Sacral osteomyelitis after robotically assisted laparoscopic sacral colpopexy. Obstet Gynecol 116:513-515

33. Collins SA, Tulikangas PK, Lasala CA, Lind LR (2011) Complex sacral abscess 8 years after abdominal sacral colpopexy. Obstet Gynecol 118:451-454

34. Mokrzycki ML, Hampton BS (2007) Pelvic arterial embolization in the setting of acute hemorrhage as a result of the anterior Prolift procedure. Int Urogynecol J 18:813-815

35. Claerhout F, Roovers JP, Lewi P, Verguts J, De Ridder D, Deprest J (2009) Implementation of laparoscopic sacrocolpopexy - a single center's experience. Int Urogynecol J 20:1119-1125 